\title{
The Effectiveness of Choice Theory Group Therapy of Glasser on Divorced Women Self-efficacy
}

\author{
Zahra Valinezhad $^{\mathrm{a} *}$, Seyed Mojtaba Aghili ${ }^{\mathrm{b}}$, Zahra Karami Baghteyfouni ${ }^{\mathrm{c}}$ \\ aDepartment of Psychology, Payame Noor University, PO BOX 19395 - 3697, Tehran, IRAN \\ ${ }^{\mathrm{b}}$ Assistant professor, Department of Psychology, Payame Noor University, PO BOX 19395 - 3697, \\ Tehran, IRAN \\ 'Assistant professor, Department of Psychology, Payame Noor University, PO BOX 19395 - 3697, \\ Tehran, IRAN \\ E-mail address: zahravalinezhad@gmail.com
}

Keywords: Choice theory, self-efficacy, divorced women.

\begin{abstract}
The purpose of the present research was to study the effectiveness of choice theory group therapy by William Glasser(1998) on divorced women self-efficacy between 18 to 23 years old. The research was semi experimental type along with pretest- past test. Using self-efficacy questionnaire (SGSES), 30 women who was of low self-efficacy were chosen on simple random and were randomly divided into experimental and control groups. Experiment group received 8 sessions treatment of Choice Theory group therapy for two months while the control group did not receive any training. After receiving training, self-efficacy was measured for next time. The collected data was analyzed by SPSS v.21 and by applying multivariate analysis covariance. The results revealed self-efficacy $(\mathrm{P}<0.05)$ significant effect. The present investigation clarified choice theory group therapy increased divorced women self-efficacy.
\end{abstract}

\section{INTRODUCTION}

Divorce is an unpredictable change in marital status having some effects on people physical and mental health and on their social position (Zare et al, 2013). Divorce is not only a socio-cultural issue but also a social determinant of health. In this regard, they have been done many studies on social, economic, psychological, juridical and biological factors influencing family health and divorce (Schramm et al, 2013 and Walid \&Zaytseva, 2011). Divorce can generally cause some harm to economy and human capital and in terms of gender analysis, it may hinder women's role in development process and at that time may exploit and marginalize them (Kalantari et al, 2011). The research by Seif (2004) revealed that Iranian divorced women suffer from the consequences of divorce more than men do. Moreover, it is expected that there is a significant relationship between demographic characteristics of divorced women and their life quality. Younger divorced women are highly vulnerable in terms of psychology, and their getting damage in social relationships is much more due to their feeling of social insecurity, so it seems that these women have lower life quality (Hafarian et al, 2009). Given that human behavior is not only controlled by environment and that cognitive processes play an important role in human behavior, it can be said that divorce as a source of stress reduces people capabilities and Self-efficacy in reaching their objectives.

Self-efficacy is a concept emphasized in learning theories. Self-efficacy is referred to as Individual judgments about their ability to successfully perform a task or job (Seif, 2008). Self efficiency beliefs determine that people will expend on an activity, how long they will persevere when confronting obstacles, and how resilient they will be in the face of adverse situations (Pajares, 2002). Perceived self-efficacy is a cognitive mechanism introduces the ability to control the scary things and makes him to be able to deal with difficulty (Cassidy\&Burnside, 1996). Feeling optimistic self-efficacy in stressful situations is more associated with adaptive coping strategies like problem-focused coping than with emotion-focused coping (Endler et al, 2001). Psychologically, self-efficacy is the perceived expectations of a person in being successful at a job or in achieving a good result from $r$ personal activities. Therefore, self-efficacy is a mental process including 
identifying objective, and estimating efforts and abilities necessary to achieve those objectives and predicting its outcomes. People with high self-efficacy believe in their abilities and persevere to get their objectives and never give up hence they are successful in convincing the other people (Evan \& Clark, 2011). One central aspect of an individual's self-efficacy is the belief that through the exertion of control one can influence the outcome of events in one's life (Bandura, 1997). Particularly when confronting stressors, retaining a sense of control over one's life is an important factor in the successful adaptation to a variety of circumstances (Aspinwall \& Richter, 1999). Control beliefs have therefore been conceptually and empirically linked with greater persistence and successful adaptation to stress; such beliefs may be an important aspect in the development of competence in resilient adolescents (Aspinwall \& Richter, 1999).

Because, divorce and separation, in many cases, result in reduction in women social relationships and even their physical health. In this way, the ability to perform physical activities decreases and thus affects a person's self-efficacy.

Also, the increase of divorce and its negative outcomes such as mood disorders, anxiety disorders, change of life style and self-concept, undermining occupational performance, change in social relationships and decrease of social support makes it more prominent to pay attention to items affecting health and compatibility after divorce. Herein, women are more vulnerable to social consequences of divorce than men (Akhavan Tafti, 2003).

Nowadays, various theoretical perspectives like cognitive, behavioral-cognitive perspectives, emotional therapy and other approaches seek to explain and solve conflicts and troubles from divorce. Choice theory is also of these approaches provided by Glaser (2000). Glaser's reality therapy approach is a unique blend of philosophy and modes of behavior that is similar to methods of self-treatment behavior of therapists (Kery, 2005). Glaser has performed many researches on choice theory demonstrating the effectiveness of this therapeutic approach. Furthermore, in choice theory, patrons are encouraged to have effective choices, because of overall behavior concept and performance component (Hosseini Ghafari et al, 2012). Reality therapy is a method based on common sense and emotional conflicts in which reality, responsibility and knowing right and wrong, and their relationships with individual daily life are emphasized. Now, there is a question that whether teaching with choice theory approach affects divorced women self efficacy.

\section{METHODOLOGY}

\subsection{Population}

This study is a quasi-experimental study included a pre-posttest design with both a treatment group and a control group. The population was all volunteer divorced women between the age of 18 and. They were selected from female adult schools of Bandar-Gaz, Iran. They were studying in 2012-2013. After completing personal characteristics and demographic information form, the populations were asked to complete the General Self-Efficacy Scale questionnaire by Sherer and Maddux (1982). Those who scored under cut-off score, 30 ones were randomly divided into two experimental and control groups of 15 participants.

\subsection{Procedure}

After randomly placing the subjects in two experimental and control groups, experimental group participated in eight 2-hour sessions of teaching (one session per week), and choice theory training started with meeting group members, explaining rules and principles of the group counseling, increasing each member's cognition and continued with being aware of themselves and presenting five basic requirements, familiarity with the concepts and principles of reality therapy and choice theory, indentifying wants or qualitative (ideal) world of perceptual world and considering present time and defining successful and unsuccessful identity, defining Serer general self efficacy and getting familiar with its components as well as knowing its educational objectives and program to achieve them the goal. A week after holding the last session, both experimental and control groups took a posttest. 


\subsection{Instrument}

Sherer and Maddux (1982) provided a measure the General Self-Efficacy Scale (GSES). It contains 17 items that are rated on a 5-point scale with the anchors agree strongly and disagree strongly (Sherer \& Adams, 1983), representing the three aspects underlying the scale; i.e. willingness to initiate behavior, Initiative, willingness to expend effort in completing the behavior, Effort, and persistence in the face of adversity, Persistence. The higher scores for these questions ( 85 as the highest score) and the lower scores (17 as the least score) represent the stronger and the weaker self-efficacy, respectively. The self-efficacy scale is previously used in several publications as depression and chronic diseases (Bisschop et al, 2004), mastery (Schuijt-Lucassen \& Deeg, 2006) and well being and deteriorating health (Jonker et al, 2009). Reliability coefficient reported by Scherer and colleagues (1982) was relatively high Cronbach alpha obtained for general selfefficacy subscale was 0.86. In Bosscher and Smith's study (1998), Cronbach's alpha coefficient for reliability was reported 0.69 and in Keramati et al. Research (1997) Cronbach's alpha coefficient for reliability was 0.85 with overall consistency questions.

\subsection{Data analysis}

Two methods were used to analyze data including descriptive statistics and inferential statistics by using SPSS statistical software V.21. Data obtained from experiment and control groups were investigated by means of descriptive indices like graph, mean and standard deviation. For Statistical analysis of data obtained from post-test questionnaires of two groups, univariate analyzes of covariance was employed regarding assumptions of normality, homogeneity of variance and homogeneity of regression slopes

\section{RESULTS}

The research's hypothesis i.e. Group therapy based on choice theory increased self-efficacy was proved.

\subsection{Descriptive statistics for dependent variable self efficacy}

Table 1 illustrated mean and standard deviation for Self efficacy of each group.

Table 1. The means and Standard deviation of divorced women self-efficacy in two stages in the experimental and control groups

\begin{tabular}{|c|c|c|c|c|c|}
\hline Variable & Stage & Group & Mean & $\begin{array}{l}\text { Standard } \\
\text { deviation }\end{array}$ & Number \\
\hline \multirow{6}{*}{ 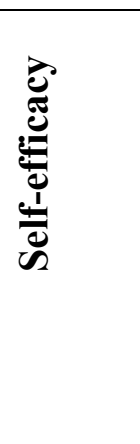 } & \multirow[t]{2}{*}{ Pretest } & Experimental & 41.47 & 8.42 & 15 \\
\hline & & Control & 41.13 & 9.04 & 15 \\
\hline & \multirow[t]{2}{*}{ Posttest } & Experimental & 47.33 & 7.71 & 15 \\
\hline & & Control & 41.6 & $8 / 69$ & 15 \\
\hline & \multirow[b]{2}{*}{$\begin{array}{l}\text { The } \\
\text { Difference } \\
\text { between } \\
\text { pretest and } \\
\text { posttest }\end{array}$} & Experimental & 6.01 & 1.77 & 15 \\
\hline & & Control & 4.01 & 1.12 & 15 \\
\hline
\end{tabular}

\subsection{Analysis of covariance}

To carry out covariance Analysis, assumptions of normality, homogeneity of variance and homogeneity of regression slopes should be investigated. 


\subsubsection{Assumptions of normality (Kolmogorov-Smirnov test)}

According to table 2, The distribution of self efficacy score in pre and post tests was 0.061 and 0.064 more than 0.05 respectively, showing that data are normal $(\mathrm{p}>0.05)$ and covariance analysis can be done.

Table 2. Normality test of self-efficacy score in pre and post tests

\begin{tabular}{|c|l|l|l|}
\hline Variable & Stage & $\begin{array}{l}\text { Kolmogorov-Smirnov test } \\
\text { statistic }(\mathrm{z})\end{array}$ & $\mathrm{P}$ \\
\hline \multirow{3}{*}{ Self-efficacy } & Pre test & 1.322 & 0.061 \\
\cline { 2 - 4 } & Post test & 1.118 & 0.064 \\
\hline
\end{tabular}

\subsubsection{Levene's test of homogeneity of variance}

The results of table 3 showed that $p$ value for self-efficacy is 0.196 that is more than 0.05 . Therefore, the variances homogeneity assumption at the level of 0.05 was confirmed. Hence, covariance analysis's results would be used for testing the hypothesis.

Table 3. The test of homogeneity variance of self-efficacy in two groups in post test

\begin{tabular}{|l|l|l|l|l|}
\hline Sariable & F & $\begin{array}{l}\text { Numerator's Degree of } \\
\text { Freedom }\end{array}$ & $\begin{array}{l}\text { Denominator's Degree } \\
\text { of Freedom }\end{array}$ & P Indexes \\
\hline Self-efficacy & 1.756 & 1 & 28 & 0.196 \\
\hline
\end{tabular}

According to table 4, $\mathrm{P}$ value for the intercept is equal to zero i.e. the intercept self-efficacy is significant. It meant that the members of the sample had a low initial level of self-efficacy.

As can be seen in table4, $\mathrm{P}$ and $\mathrm{F}$ values for the variable group were 0.007 and 8.817 respectively. It can be concluded that divorced women self-efficacy variable in post-test in group is significantly different. Also, $\mathrm{p}$ and $\mathrm{f}$ values for pre test were 0.970 and 0 ; therefore, the pretest effect on post test is significant. It meant that the dependent variables are significantly related to pretest effect. Also $\mathrm{p}$ and $\mathrm{f}$ values for group and pre test effect 0.350 and 0.034 respectively. It meant that the interaction between group variable and pre test effect is not significant and the data supports the hypothesis of homogeneity of regression slopes.

Eta squared value for the group and pre test is 0.251 and 0.970 . It indicated that group therapy based on choice theory significantly influenced experimental group. 
Table 4. Results of univariate analysis of covariance on self-efficacy posttest scores in experimental and control groups controlling effect of pre-test

\begin{tabular}{|c|c|c|c|c|c|c|c|}
\hline source & Sum of squares & $\begin{array}{c}\text { Degree } \\
\text { of } \\
\text { Freedom }\end{array}$ & Mean squares & Squares Mean & F & P & $\begin{array}{c}\text { Eta } \\
\text { Squared }\end{array}$ \\
\hline intercept & 47.4 & 1 & 47.4 & 22.025 & .71 & .458 & .995 \\
\hline Group & 18.77 & 1 & 18.77 & 8.72 & .007 & .251 & .811 \\
\hline Pre test & 1815.251 & 1 & 1815.251 & 843.133 & 0.55 & .97 & 1 \\
\hline $\begin{array}{c}\text { Group and pre } \\
\text { test effect }\end{array}$ & 1.95 & 1 & 1.95 & .9 & .35 & .034 & .9 \\
\hline Error & 55.98 & 26 & 2.153 & & & & \\
\hline Total & 61456 & 30 & & & & \\
\hline
\end{tabular}

\subsubsection{Adjusted means}

Adjusted means of the two groups were presented in Table 5 in which pre test effect was not considered and experimental group compared with control group had enhanced self-efficacy.

Table 5. Adjusted means of self-efficacy variable in both control and experimental groups

\begin{tabular}{|c|c|c|c|c|}
\hline \multirow[t]{2}{*}{ Group } & \multirow[t]{2}{*}{ Mean } & \multirow[t]{2}{*}{ Standard deviation } & \multicolumn{2}{|c|}{ Confidence interval 95\% } \\
\hline & & & Lower limit & upper limit \\
\hline$\overline{C G}$ & 41.756 & 0.379 & 40.980 & 42.538 \\
\hline EXG & 47.184 & 0.379 & 46.405 & 47.963 \\
\hline
\end{tabular}

The overall results obtained from the analysis of covariance and adjusted mean scores on the self-efficacy indicated that the variables in the experimental group in post test compared to the control group significantly increased. Therefore, the hypothesis was confirmed. In other words, effectiveness of choice theory enhanced self-efficacy in experimental group compared with the control group.

\section{RESULT AND DISCUSSION}

Reality Therapy helps people by taking the responsibility, which is considered as the hallmark of mental health, to take effective control of their own lives and effectively meet their needs. Weird behavior resulting from failure identity, lack of attention to facts, an inability to conduct the evaluation and selection of their own behaviors often result in undesirable consequences (Shafie Abadi, 2000; Shillingford \& Edwards, 2008; Sharf, 2007; and Glaser, 2000). Thus, training principles of choice theory can play an important role in motivating a person and in being aware of their abilities. This seems that this method, in addition to its treatment attributes, has preventive and developmental roles as well. Thus, training choice theory may help women to prevent the problems related to divorce. In this regard, this method can be offered to those who typically and generally deal with separation and loneliness and difficulty in their relations. The proliferation of this idea can be used in family meetings. In addition, it is necessary that future researches investigated the efficacy of this method on other aspects of relations and promote effective communication. On the other hand, it can be concluded that group reality therapy sessions concentrating on successful identity, satisfying basic needs, an informed choice of correct behavior, the present time, taking responsibility and having a purpose and a plan to achieve it make divorced women gain positive experiences and identities through responsible behavior in life and dealing with problems and then realize the importance of choosing the correct behavior in their own lives. 
All in all, the Hypothesis of the study, that is, training choice theory has a significant effect on experimental group was confirmed. In other words, choice Theory training enhanced self-efficacy in experimental group compared with control group. The findings of the current research were in line with the research results from Abolghasemi\& Jafari (2012); Rahimian Boogar et al (2011); Kar kianoush et al, (2010); and JahanMalki (1997).

\section{CONCLUSION}

Using self-efficacy questionnaire (SGSES), 30 women who was of low self-efficacy were chosen on simple random and were randomly divided into experimental and control groups. Experiment group received 8 sessions treatment of Choice Theory group therapy for two months while the control group did not receive any training. After receiving training, self-efficacy was measured for next time. The collected data was analyzed by SPSS v. 21 and by applying multivariate analysis covariance. The results revealed self-efficacy $(\mathrm{P}<0.05)$ significant effect. The present investigation clarified choice theory group therapy increased divorced women self-efficacy.

\section{References}

[1] Abolghasemi, A., \& Jafari, E. (2012). The Effectiveness of Dialectical Behavior Therapy on Body Image and Self-Efficacy in Girls with Bulimia Nervosa. 2(14):29-37.

[2] Akhavan Tafti, M. (2003). Consequences of divorce in the tradtion stages, women's studies, 1(3): 127-151.

[3] Aspinwall, L.G., \& Richter, L. (1999). Optimism and self-mastery predict more rapid disengagement from unsolvable tasks in the presence of alternatives. Motivation and Emotion, 23: 221-245.

[4] Bandura, A. (1997). Self-efficacy: The exercise of control. New York: W. H. Freeman.

[5] Bisschop, M. I., Kriegsman, D. M., Beekman, A. T., \& Deeg, D. J. (2004). Chronic diseases and depression: the modifying role of psychosocial resources. Soc Sci Med. 59(4):721-33.

[6] Bosscher, R.J., \& Smit, J.H. (1998). Confirmatory factor analysis of the General Self-Efficacy Scale. Behaviour Research and Therapy, 36: 339-343.

[7] Cassidy,T., \& Burnside, E. (1996). Cognitive appraisal, Vulnerability and coping: An integrative analysis of appraisal and coping mechanisms, counseling psychology quarterly, 9: 261-279.

[8] Endler, N. S., Speer, R. L., Johnson, J. M., \& Flett, G. L. (2001). Controllability, coping, efficacy and distress. European Journal of Personality, 21: 422-445.

[9] Evans, A., \& Clark, J. (2011). Source characteristic and Persuasion, Journal of Experimental Social Psychology, 9: 15-31.

[10] Glasser, W. (1998). Choice Theory, New York: HarperCollins.

[11] Glasser,W. (2000), Counseling with choice therapy: The new reality therapy. New York: Harper-Collins.

[12] Hafarian, L., Aghaei, A., Kajbaf, M., Manouchehr, B., \& Kamkar, M. (2009). Comparison of quality of life in non-divorced and divorced women and its relationship with demographic characteristics in Shiraz, Journal of Knowledge and Research in Applied Psychology, 11(41): 61-82.

[13] Herbert, J. D., Gaudiano, B. A., Rheingold, A. A., Myers, V. H., Dalrymple, K., Nolan, E. M. (2005). Social Skills Training AugmentsThe Effectiveness of Cognitive Behavioral Group Therapy For Social Anxiety Disorder. Journal of Behavior Therapy, 36: 125-138. 
[14] Hosseini Ghafari, F., Ghanbari Hashem Abadi, B., \& Agha Mohamadian Sherbaf, H. (2012). The effectiveness of group therapy based on motivational choice theory and treated systematically increasing marital satisfaction, Journal of studies in education, 9(2): 65-78.

[15] JahanMalki, S. (1997). The relationship between the levels of awareness of life skills whit self confident believes in the students of Shahid Beheshti University, Thesis of M.A University of Shahid Beheshti.

[16] Jonker, A.G.C., Comijs, H.C., Knipscheer, C.P.M., \& Deeg, D.J.H. (2009). The role of coping resources on change in well-being during persistent health decline. Journal of Aging and Health, 21(8): 1063-1082.

[17] Kalantari, A., Roshanfekr, P. \& Javaheri, J. (2011). The Effects and Consequences of Divorce: systematic review of the researches performed in Iran with an emphasis on gender notifications. Journal of Women in Development and Politics, Ninth period, issue 3: 111-131.

[18] Kar kianoush, Z., Reza zadeh, A., \& Ghodsi, A. (2010).The efficacy of problem-solving skills training, self-efficacy of female high school students in Rasht city, journal of new ideas in education .3 (9): 134-150.

[19] Keramati, H., \& Farahani , M. (1997). Examine the relationship between self-efficacy and attitudes toward mathematics achievement in third grade pupils in Tehran. Journal of Alzahra.

[20] Kery, J. (2005). Theory and practice of counseling and psychotherapy, Translated by Seyed Mohammadi Y. Tehran: Arasbaran.

[21] Pajares, F. (2002). Overview of social cognitive therapy and self-efficacy, Retrieved month, day, year, from http: //www. emory. Edu/education/eff.

[22] Rahimian Boogar, E., Besharat, MA., Mohajeri Tehrani, MR., \& Talepasand, S. (2011). Predictive Role of Self-Efficacy, Belief of Treatment Effectiveness and Social Support in Diabetes Mellitus Self-Management, Journal of Psychiatry and Clinical Psychology. 17(3): 232- 240.

[23] Schramm, D. G., Harris, S. M., Whiting, J. B., Hawkins, A. J., Brown, M., \& Porter, R. (2013). Economic Costs and Policy Implications Associated With Divorce: Texas as a Case Study. Journal of Divorce \& remarriage, 54(1): 1-24.

[24] Schuijt-Lucassen , N. Y., \& Deeg, D. J. (2006). Predicting loss of mastery in older adults. Tijdschr Gerontol Geriatr. 37(6): 243-53. Seif, S. (2004). The differential study of outcome divorce rate in Iranian and American men and women. Family and Research, 1(1): 81-104.

[25] Seif, A. (2008). Psychology of Learning and Instruction. 2 end. Tehran: Doran.

[26] Shafie Abadi, A. (2000). Guidance and advice Education and Career. Tehran: Semat.

[27] Sharf, S. (2007), Theories of Psychotherapy and Counseling. Teranslated by Firouz Bakht M. Tehran: Rasa.

[28] Sherer, M., \& Maddux, J. E. (1982). The self-Efficacy scale: construction and validation psychological Report. 51: 63-671.

[29] Sherer, M., \& Adams, C. H. (1983). Construct validation of the self-efficacy scale. Psychological Reports. 53: 899-902.

[30] Shillingford, M. A., \& Edwards, O,W. (2008). Application of Choice Theory with a Student Whose Parent is Incarcerated, International Journal of Reality Therapy, vol.XXVIII,number 1.

[31] Zarei, F., Merghati Khoei, E., Taghdisi, MH., Mahnaz, S., Nejat, S., Shojaei Zadeh, S., Rajati, F., \& Rahmani, A. (2013). Divorce from a divorcee woman's perspectives: A qualitative study. J. Quality research health Sci. 2(3): 234-247.

[32] Walid, M. S., \& Zaytseva, N. V. (2011). which neuropsychiatric disorder is more associated with divorce? Journal of Divorce\& Remarriage, 52(4): 220-224. 